\title{
An Audiomagnetotelluric View of the Atera Fault
}

\author{
Y. OGAWA ${ }^{1}$ and Y. HoNKURA ${ }^{2}$ \\ ${ }^{1}$ Geological Survey of Japan, 1-1-3 Higashi, Tsukuba, Ibaraki 305, Japan \\ ${ }^{2}$ Department of Earth and Planetary Sciences, Tokyo Institute of Technology, Ookayama, Tokyo 152, Japan
}

(Received February 1, 1996; Revised January 29, 1997; Accepted April 25, 1997)

\begin{abstract}
We made audiomagnetotelluric sounding to image the subsurface structure across the Atera fault, which is a $66 \mathrm{~km}$ long active strike-slip fault in central Japan. A major feature of the resistivity model is existence of two dipping conductors at $0.5-2.0 \mathrm{~km}$ depth: one dipping southwest and the other northeast. These imply fractured zones, created either by strike slip movements or by vertical ones. An audiomagnetotelluric imaging is suited for mapping subsurface fractures zones in active fault regions.
\end{abstract}

\section{Introduction}

The Atera fault system is a $66 \mathrm{~km}$ long left-lateral strike-slip fault running in the NW-SE direction in Central Japan, as shown in Fig. 1. Studies on geomorphology and surface geology revealed its historical activity over fifty thousand years, and the average horizontal slip rate of this fault has been estimated as $2.8 \mathrm{~mm} /$ year and the recurrence interval as 2000 years (Tsukuda et al., 1993). The slip rate is one order of magnitude smaller than the typical rate of plate motion, but the rate of $2.8 \mathrm{~mm} /$ year is very large for intraplate faults and the Atera fault is classified as 'rank A', among active faults in Japan. Present seismic activity is low and no other activity such as crustal deformation is observed in this area.

Compared with geomorphologic and geologic studies, very few geophysical studies have been undertaken for the subsurface structure of the Atera fault system. From a gravity compilation, Yamamoto et al. (1982) and Shichi et al. (1992) showed a notch-shaped low Bouguer anomaly along the Atera fault system. Its approximate width and amplitude are $5 \mathrm{~km}$ and $2 \mathrm{mgal} \mathrm{re}-$ spectively (Yamamoto et al., 1982). The low anomaly spreads further beyond the surface traces of the fault system both in northwest and southeast directions. In view of gravity, the Atera fault is recognized as a large tectonic line. The low anomaly was interpreted as representing the fault gouge material of low density, but no specific structure model was derived because of the difficulty in estimating the density contrast. Murakami et al. (1984) measured geomagnetic total force across the fault, but they could not find significant and consistent anomalies associated with the fault. A shallow seismic reflection survey was carried out by Yamaguchi et al. (1985), but unsuccessful to obtain a clear subsurface image across the known fault traces. The subsurface structure of the Atera fault area has thus remained almost unknown, in relation to surface fault traces.

Another geophysical survey is an electromagnetic sounding which aims at obtaining information on electrical properties of subsurface material. In particular, the resistivity of crustal rock at shallow depths is controlled mainly by conducting fluid, which fills pores and cracks. Fractured zones which often develop along active fault traces are characterized by high porosity and hence by low resistivity. In fact, some examples of low resistivity zones have been reported in association with fractured zones along active faults (e.g., Electromagnetic Research Group for the Active Fault, 1982, 1983; Ogawa et al., 1994; Unsworth, personal communication, 1996).

The objective of this study is to reveal the subsurface structure of the Atera fault by magnetotellurics and to put geophysical constraints on the fault system. 


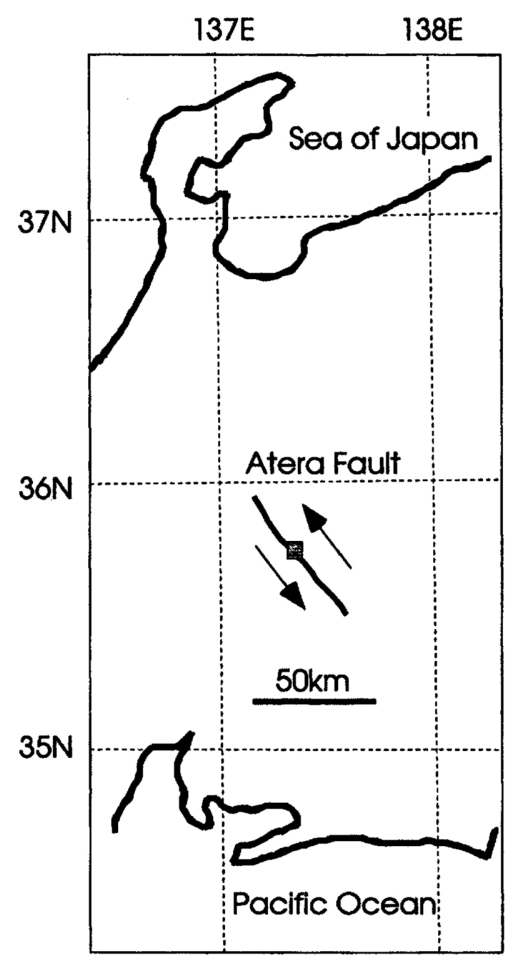

Fig. 1. Location of the Atera fault system in central Japan. The small rectangle indicates the observation area.

\section{Data Acquisition and Processing}

We made magnetotelluric sounding in the audio-frequency range, which is usually called audiomagentotellurics (AMT), across the central part of the Atera fault system in December, 1995. The study area is shown by the small rectangle in Fig. 1. Fault traces in this area have been clearly identified at the surface. As shown in Fig. 2, in the study area, the Atera fault system has three parallel fault traces: the Gero fault, the Kowachi fault and the Yugamine fault.

We used the V5-AMT system manufactured by Phoenix Geophysics Ltd., Canada. We measured two horizontal components of the electric field and three components of the magnetic field at 12 sites. The frequency range was from $1 \mathrm{~Hz}$ to $1 \times 10^{5} \mathrm{~Hz}$. It took 3 to 10 hours to acquire sufficient data for this frequency range.

Vertical magnetic field data are of reasonable quality only for 3-100 Hz. Figure 2 shows the distribution of real induction arrows at $10 \mathrm{~Hz}$. The arrows point perpendicular to the surface fault traces. This means that the electrical regional strike is consistent with the surface fault traces. The arrows at sites in the northeast of the faults are all small. This suggests that the northeastern side of the fault is more conductive.

In order to interpret the MT data in terms of a two-dimensional model, we must first find a regional strike direction consistent over the area. For this we used the extended codes of Groom-Bailey decompositions (Groom and Bailey, 1989; McNeice, 1994), in which the strike is both frequency- and site-independent, and the twist and the shear are frequency-independent and site-dependent. The regional strike thus calculated for each decade of frequencies shows clockwise rotation with decreasing frequencies: $\mathrm{N} 60^{\circ} \mathrm{W}$ for $10,000-1,000 \mathrm{~Hz}, \mathrm{~N} 50^{\circ} \mathrm{W}$ for 1,000 


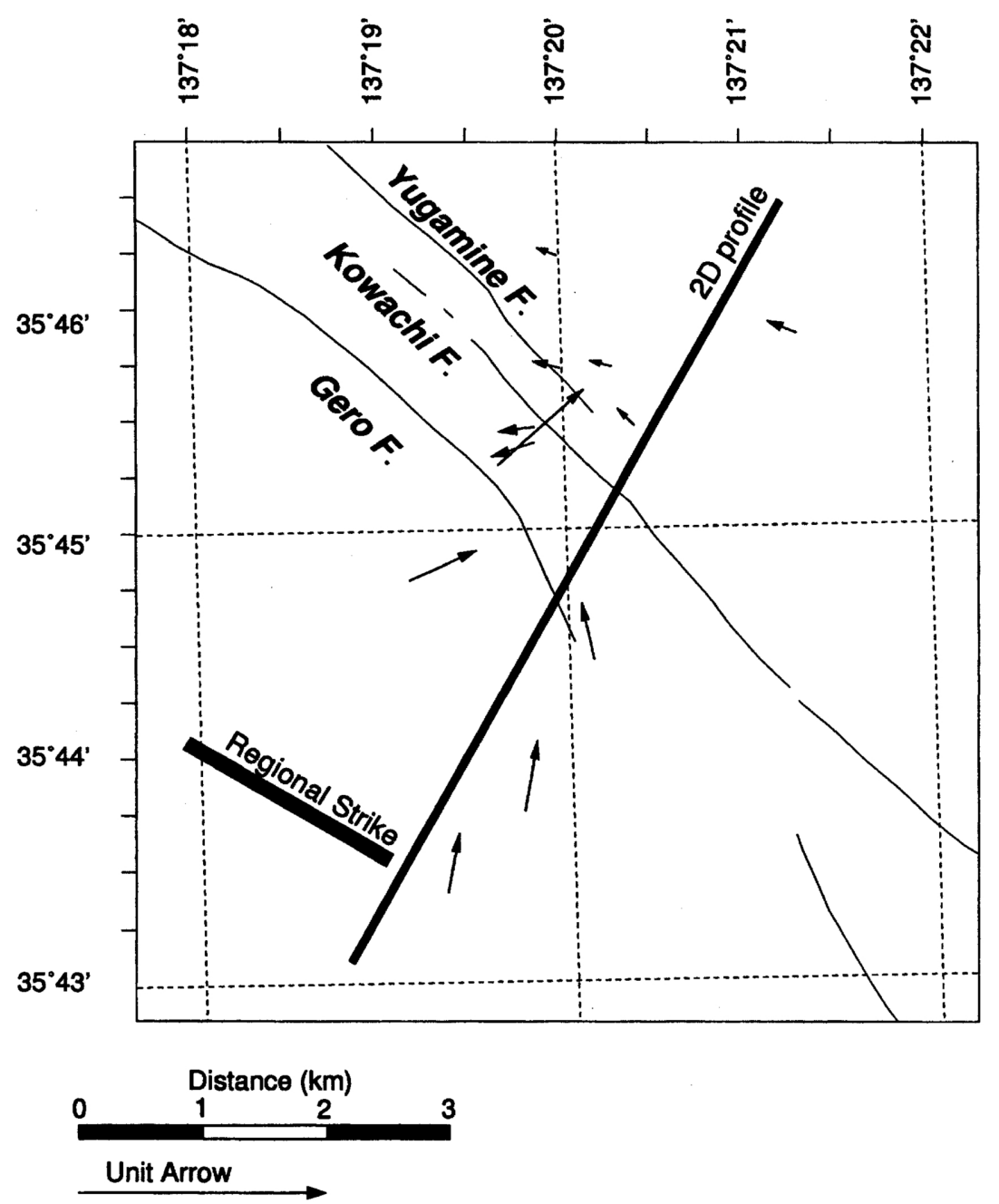

Fig. 2. Distribution of real induction arrows at the frequency of $10 \mathrm{~Hz}$. The surface fault traces are also shown (Tsukuda et al., 1993). Also shown are the regional strike of $\mathrm{N} 31^{\circ} \mathrm{W}$ and a corresponding profile direction for a two-dimensional modeling.

$100 \mathrm{~Hz}, \mathrm{~N} 31^{\circ} \mathrm{W}$ for $100-10 \mathrm{~Hz}$, and $\mathrm{N} 20^{\circ} \mathrm{W}$ for $10-1 \mathrm{~Hz}$. Emphasizing relatively deep structure, we adopted $\mathrm{N} 31^{\circ} \mathrm{W}$ as a regional strike. In the magnetotellurics the strike direction determined from the impedance tensor has ambiguities of $\pi / 2$. Thus $N 59^{\circ} \mathrm{E}$ is also a best fitting strike direction. As shown in Fig. 2, the induction arrows as well as the fault traces prefer a regional strike of $\mathrm{N} 31^{\circ} \mathrm{W}$.

All the impedance data were again decomposed with the strike fixed at $\mathrm{N} 31^{\circ} \mathrm{W}$. To overview the dataset, we made pseudosections for decomposed data. Figure 3(a) shows the TM mode apparent resistivity. Hereafter positions are referred to by the distance on the horizontal coordinate ( $x$-axis). The surface low resistivity affects all the frequencies at $x=0 \mathrm{~km}$. Figure 3(b) shows the TM mode phase. There is a high $\left(>45^{\circ}\right)$ phase region at the highest frequencies at around $x=0$. Another notable feature is a region extending horizontally at the frequencies of around $100 \mathrm{~Hz}$. Figure 3(c) shows the TE mode apparent resistivity. There are low resistivity 
(a)

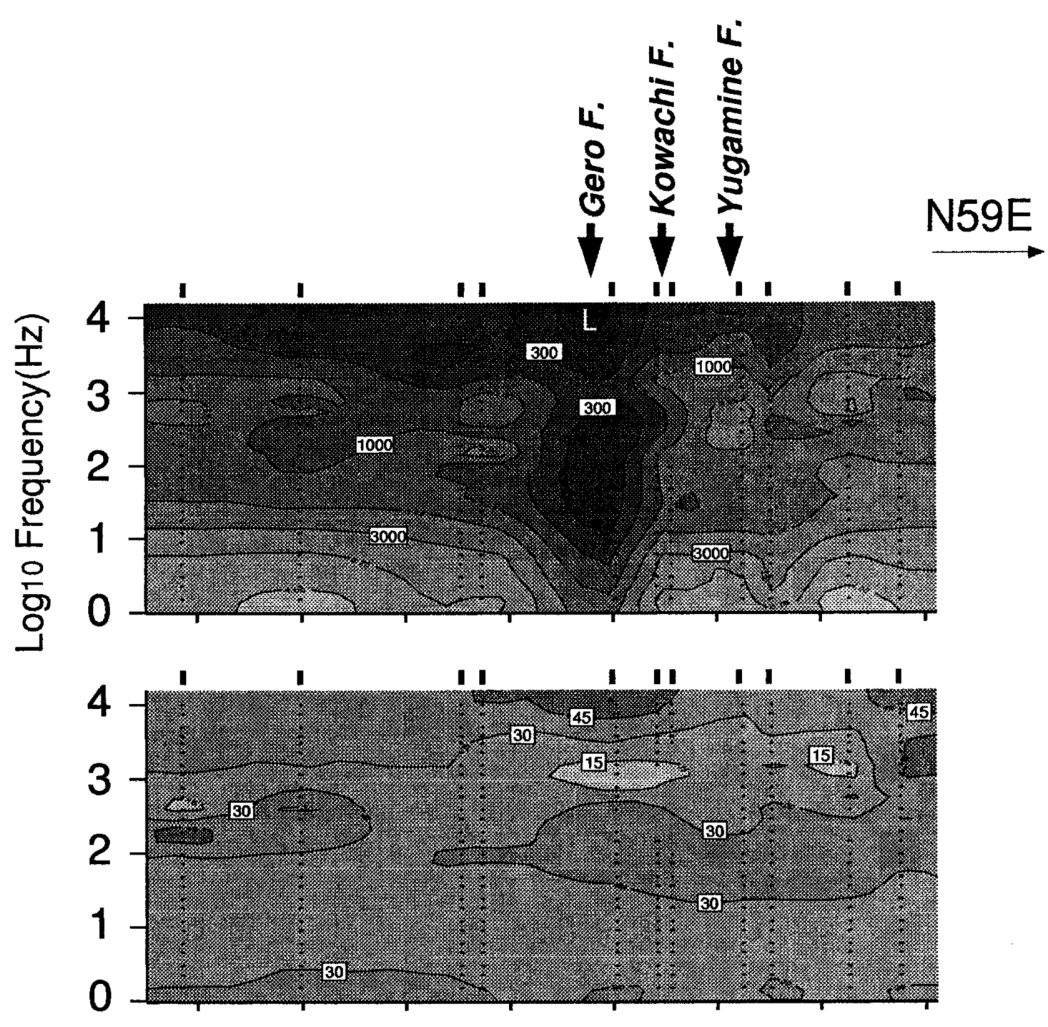

(c)

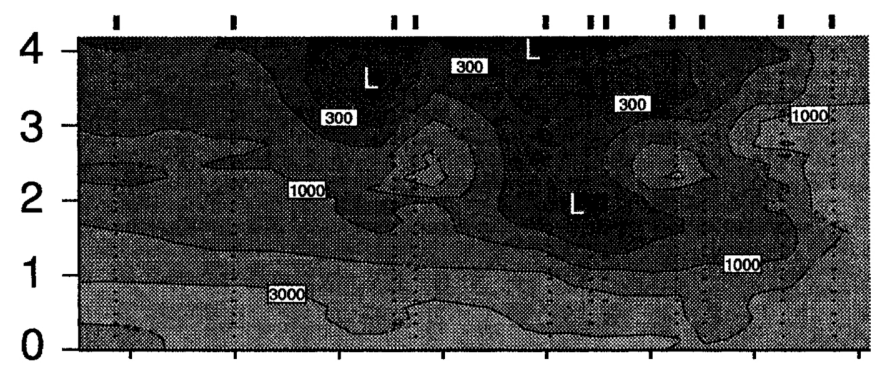

(d)

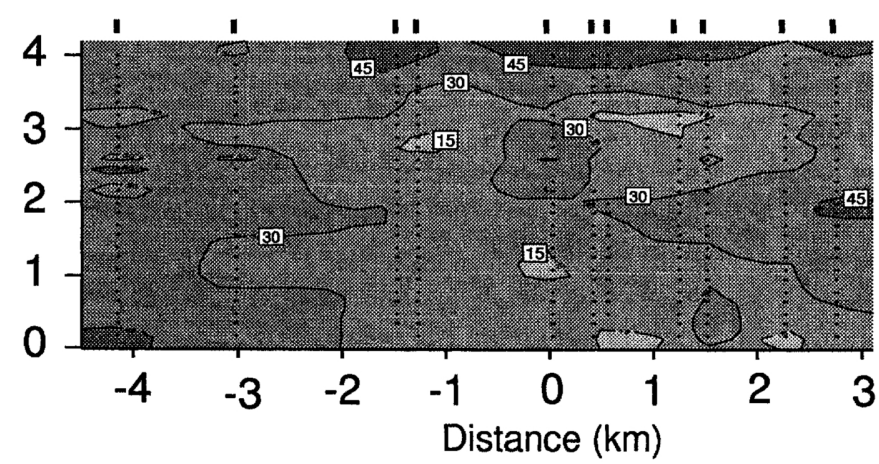

Fig. 3. Pseudosections of (a) the TM mode apparent resistivity, (b) the TM mode phase, (c) the TE mode apparent resistivity, and (d) the TE mode phase. F denotes the location of surface fault traces (Tsukuda et al., 1993). 
(a)

(b)

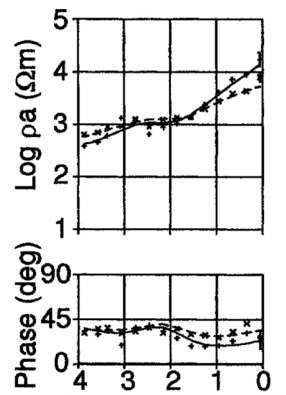

Log Frequency $(\mathrm{Hz})$
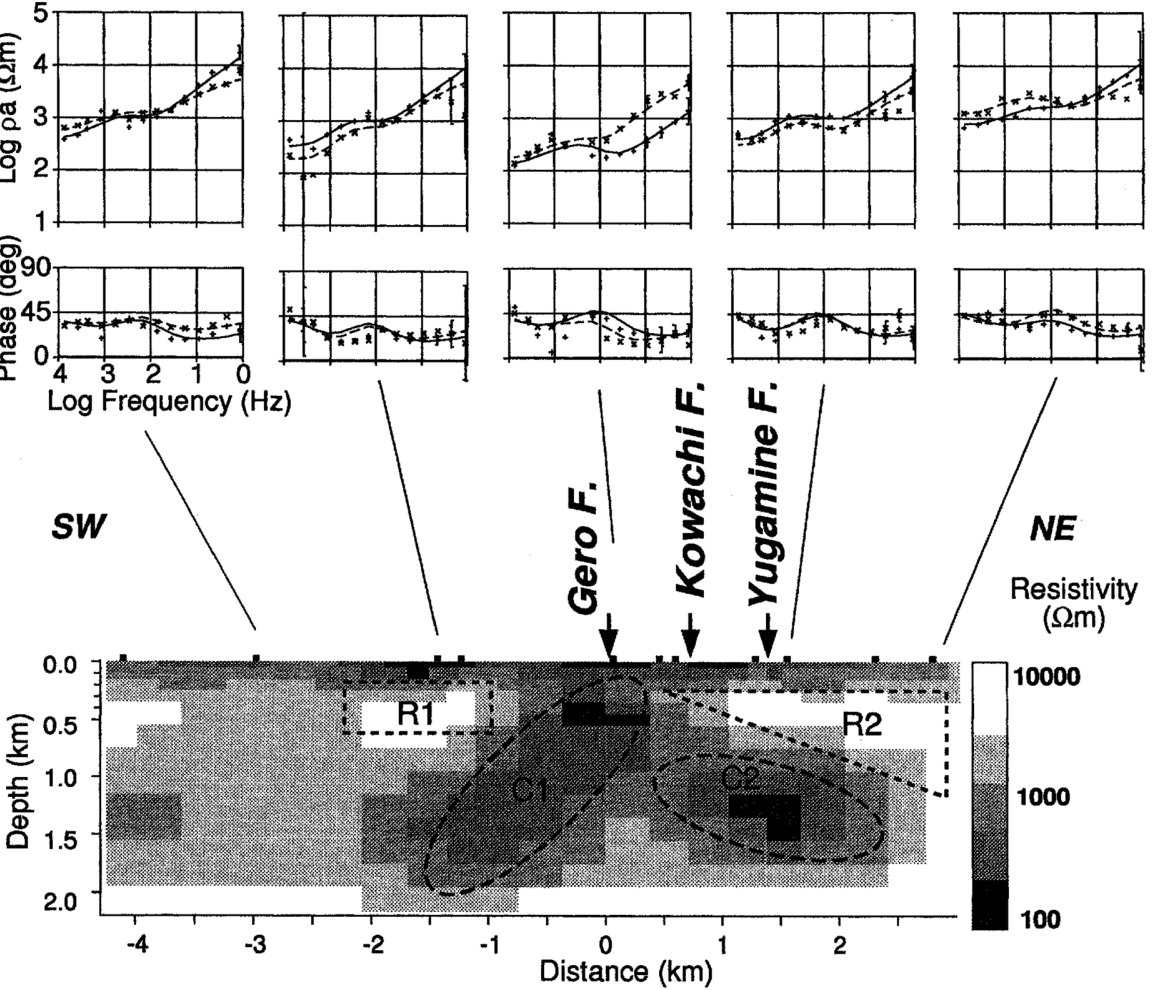

(c)

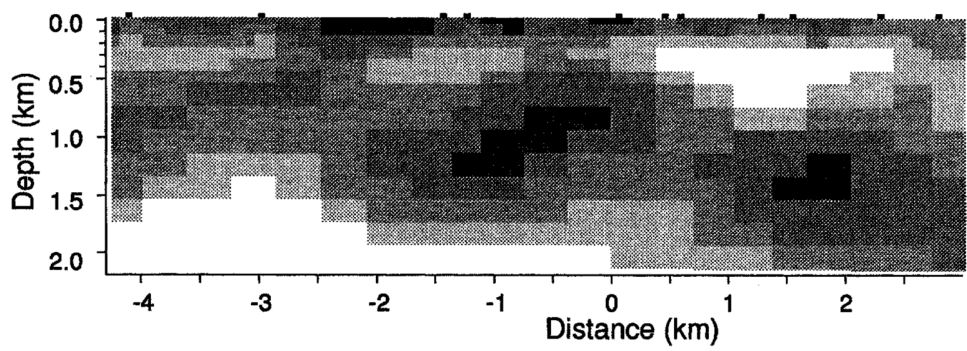

(d)

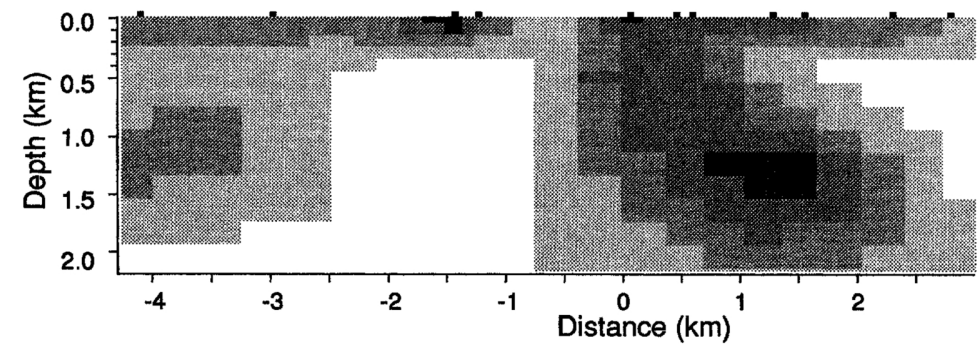

Fig. 4. (a) Typical apparent resistivity and phase data, which are decomposed with the strike fixed in the direction of $\mathrm{N} 31^{\circ} \mathrm{W}$. The corresponding site locations are shown in the lower panel. The observed TE and TM data are shown by cross and plus signs, respectively. The model TE and TM curves are shown by solid and broken lines, respectively. (b) The optimum model derived using both TE and TM mode data. F denotes the locations of surface fault traces (Tsukuda et al., 1993). $C_{1}$ and $C_{2}$ denote two significant conductive features. (c) The optimum model using only TM mode data. (d) The optimum model using only TE mode data. 
$(<300 \Omega \cdot \mathrm{m})$ regions at $x=-1.5 \mathrm{~km}$ and $x=0 \mathrm{~km}$ and the vicinities. The latter extends toward the lower right corner in the figure. Figure 3(d) shows the TE phase pseudosection. A relatively high region at $x=0$ extends to the right end in the figure.

\section{Two-Dimensional Modeling}

Figure 4(a) shows the decomposed apparent resistivity and phase values at five representative sites. We used the decomposed apparent resistivity and phase data for both TM and TE modes. The process for determining the static shift parameters is included in the two-dimensional inversion scheme, in which misfit is minimized under the dual constraint on the minimum model roughness and the minimum static shift $L 2$ norm (Ogawa and Uchida, 1996). As an initial model, we adopted a uniform resistivity earth of $100 \Omega \cdot \mathrm{m}$. The error floor was assumed as $20 \%$ for the apparent resistivity and an equivalent for the phase. The final rms reached 1.35, indicating that the fitting of the apparent resistivity was within $27 \%$.

The optimum model is shown in Fig. 4(b). Curves in Fig. 4(a) show responses of this model including static shifts. We also tried inversions using TE mode only and TM mode only. The corresponding models are shown in Figs. 4(c) and (d), respectively. From these we can tell the sensitivity of the model to the data.

\section{Discussion and Concluding Remarks}

Here we discuss the implications of the resistivity model (Fig. 4(b)). The model is generally characterized by high $(>1000 \Omega \cdot \mathrm{m})$ resistivity. This implies the distribution of the Nohi rhyolites in the Jurassic age (Tsukuda et al., 1993). There are shallow ( $<200 \mathrm{~m} \mathrm{depth)} \mathrm{conductors} \mathrm{in}$ Fig. 4(b). They will imply the distribution of sedimentary layer, such as terrace deposits and alluvium, which are seen around the fault traces (Tsukuda et al., 1993).

The deeper structure has two significant conductors, shown as $C_{1}$ and $C_{2}$ in Fig. 4(b). $C_{1}$ is dipping toward southwest, while $C_{2}$ is dipping toward northeast. $C_{1}$ is more vertical and is connected to one of the surface traces: the Gero fault (Fig. 2). On the other hand $C_{2}$ is not connected to the surface. We can check the sensitivity of the model to the data by two additional inversions using TE mode data only (Fig. 4(d)) and TM mode data only (Fig. 4(d)). Both conductors are seen in the Fig. 4(c) and are required mostly from TM mode. The TE mode result (Fig. $4(\mathrm{~d})$ ) require only $C_{2}$ conductor. This difference comes from the different sensitivity of the two modes to the buried conductor. A significant structure from the TE mode is the resistive block at $-2.5 \mathrm{~km}<x<-1 \mathrm{~km}$ below $300 \mathrm{~m}$ depth. It is also seen in the joint mode inversion result (Fig. 4(b)) as a resistive block $R_{1}$ at the similar location but only within shallower part.

The dipping nature of the two conductors has implications for vertical displacements. The geological and geomorphological studies showed that the Atera fault system has $700 \mathrm{~m}$ vertical displacement in total as well as 3-7 km of left-lateral displacement (Yamada, 1981). The northeast side moved up relative to the southwest. The surface topography at the study region shows the depression in between the Gero and the Yugamine faults (Tsukuda et al., 1993). The Gero fault shows uplift in the southwestern side and the Yugamine fault has uplift in the northeastern side. The Kowachi fault in between does not show consistent uplift in the study region. If the two structures of (1) $R_{1}$ over $C_{1}$ and (2) $R_{2}$ over $C_{2}$ imply thrusting toward $x=0$, the thrust polarity matches the surface topography. Actually, a recent outcrop study at the Atera fault system (Toda et al., 1994) showed a nature of the low angle thrust faulting.

Our two conductors $\left(C_{1}\right.$ and $\left.C_{2}\right)$ imply fracture zones created not only by strike slip motion but also by thrust faulting. Their horizontal spread is $4 \mathrm{~km}$ and is comparable to that of the low gravity anomaly (Yamamoto et al., 1982). Electromagnetic soundings in active fault regions will 
help allocate subsurface fracture zones and give information on the fault geometry. More spatial coverage and lower extension of the frequency range are necessary for imaging of the whole fault system.

Hidekuni Kuroki and Tetsuyuki Abe contributed to the field work. YO thanks Alan Jones, Gary McNeice, and Jim Craven for helping him with the tensor decompositions. Critical comments from Takesi Yukutake and an anonymous referee improved the manuscript very much.

\section{REFERENCES}

Electromagnetic Research Group for the Active Fault, Low electrical resistivity along an active fault, the Yamasaki Fault, J. Geomag. Geoelectr., 34, 103-127, 1982.

Electromagnetic Research Group for the Active Fault, Electrical resistivity structure of the Tanna and the Ukihashi faults, Bull. Earthq. Res. Inst., Univ. Tokyo, 58, 265-286, 1983 (in Japanese with English Abstract).

Groom, R. W. and R. C. Bailey, Decomposition of magnetotelluric impedance tensor in the presence of local three-dimensional galvanic distortion, J. Geophys. Res., 94, 1913-1925, 1989.

McNeice, G. W., Magnetotelluric investigation of the Appalachian Orogen, Newfoundland, Canada, M.Sc. Thesis, Memorial Univ. of Newfoundland, 1994.

Murakami, H., I. Yamada, and U. Kobayashi, Geomagnetic total force anomalies associated with active faultsobservation of the geomagnetic total force around Atotsugawa and Atera fault, Zisin 2, 37, 397-405, 1984.

Ogawa, Y., M. Uyeshima, Y. Honkura, H. Utada, and S. Koyama, Audio-frequency magnetotelluric imaging of an active strike-slip fault, J. Geomag. Geoelectr., 46, 403-408, 1994.

Ogawa, Y. and T. Uchida, A two-dimensional magnetotelluric inversion assuming Gaussian static shift, Geophys. J. Int., 126, 69-76, 1996.

Shichi, R., A. Yamamoto, A. Kimura, and H. Aoki, Gravimetric evidences for active faults around Mt. Ontake, Central Japan: Specifically for the hidden faulting of the 1984 western Nagano prefecture earthquake, J. Phys. Earth., 40, 459-478, 1992.

Toda, S., D. Inoue, N. Takase, A. Kubouchi, and N. Tomioka, The latest activity of the Atera fault: A possibility of the 1586 Tensho Earthquake, Zisin 2, 47, 73-77, 1994 (in Japanese).

Tsukuda, E., Y. Awata, H. Yamazaki, Y. Sugiyama, K. Shimokawa, and K. Mizuno, Explanatory text of the strip map of the Atera fault system, Geological Survey of Japan, scale 1:25,000, Tectonic map series (7), 39 pp., 1993 (in Japanese with English abstract).

Yamada, T., The Atera fault: -Its geological background-, Chikyu Monthly, 3, 237-243, 1981 (in Japanese).

Yamaguchi, K., S. Watanabe, N. Kano, and T. Yokokura, Reflection seismic survey of the Atera fault, Proc. Soc. Explor. Geophys. Japan, Fall Meeting, 57-58, 1985 (in Japanese).

Yamamoto, A., K. Nozaki, Y. Fukao, M. Furumoto, R. Shichi, and T. Ezaka, Gravity survey in the central ranges, Honshu, Japan, J. Phys. Earth, 30, 201-243, 1982. 